\title{
Financing Patterns of Highway Construction Under the PPP Model
}

\author{
Suhui Guo \\ Tianjin University, Tianjin, 300072, China
}

Keywords: Highway construction, PPP model, Financing risk

\begin{abstract}
To adapt to the needs of economic development and people's production and life, many areas are speeding up highway construction projects. However, highway construction is a large-scale construction project, which needs large amounts of capital and is easy to block in financing. This paper analyzes the main problems facing the financing of highway construction at the present stage and gives some suggestions on the PPP financing model in highway construction, including perfecting legal system, reducing finance risk and strengthening construction management to provide some references for the relative researchers.
\end{abstract}

\section{Introduction}

PPP financing model refers to the new financing mode of building or providing public goods and services through the way of public and private cooperation [1]. To provide public goods and the traditional financing mode led by the government and fiscal expenditure as the main source of funds than in the financing mode, government or other public sector to meet the social public needs, one or more links in the feasibility analysis and planning of the project after the initial design, through bidding, the bidder selection of private sector to be responsible for project construction, operation and maintenance, and the private sector to pay a fee or give a certain degree of preferential policies to encourage and attract more social capital investment. Between the government and the private sector, it is necessary to clarify the rights and obligations of the two parties through signing the corresponding contracts, taking the sharing of benefits, risks and social responsibilities as the guidelines of action, so that the cooperation between the two departments of the public and private sectors is more effective than any single department's actions. PPP model has a strong promotion value in the construction of public products, such as transportation, health, public safety, national defense, education, public real estate management and so on. As a new type of project investment and financing mode, PPP mode is to carry out investment and financing business according to the expected revenue, assets and government support measures. Among them, the main sources of loan repayment are two aspects: one is the direct benefit of project management; the other is the transformation benefit from government support. The limited commitments of the government and the assets of item company can effectively guarantee the ability to repay loans. In the project, more private capital can be introduced through the PPP model, so that the efficiency of investment and financing is improved and the risk is further reduced. In this way, the construction cycle of the project can be shortened greatly, and the operation cost and even the asset liability ratio of the project are greatly reduced [2].

\section{Main Problems Facing the Financing of Highway Construction}

\subsection{Single Financing Body}

The imperfections of the system are obvious. Our country has not yet established a system of efficient financial market, and there is no sound policy environment and financing system. The existing methods are lack of systematisms and perfection, and there are few legal protection contents for the entry of intermediate capital. At present, China's provincial transportation department is mainly responsible for investment and financing of highway construction in the province, but as 
government departments, which cannot be directly facing the market financing, the current mainly rely on bank loans, transportation fees, toll revenue, Ministry of transport, financial subsidies and other funds for road construction, there is no other channels can rely on. The data indicate that the credit financing space is approaching the limit under the current conditions, and the demand for expressway construction funds has exceeded the financing capacity of the competent department. Not only are private enterprises qualified to participate in highway construction through the PPP financing model, but also the state-owned enterprises. Through the mode of financing, state-owned enterprises can not only cooperate with the local government financing, but also with other social capital to participate in the construction of highway, private capital, fund companies, cross regional investment, no matter what kind of cooperation, are to be established in laws and regulations clearly have effectively to the project. We can also see that the diversity of social capital themes of financing cooperation is conducive to the operation of highway construction projects and has positive significance for long-term road construction [3].

\subsection{Difficult Market-based Financing}

The construction cycle of the expressway is long, the construction environment is complex, the technical content is high, and the demand for funds is large. In the current economic situation, the local government's financial budget is limited, and it is at the peak of debt service. China's fiscal and tax policies have greatly promoted the construction and development of highway infrastructure, and the scale of the mileage of the highway in China is the first in the world. We have also accumulated a heavy debt burden. The freeway charge policy is divided into the following stages: the first stage is that the highway construction relies solely on financial investment and is bound by financial financial and financial input. The second stage is the State Council's policy of lending roads and charging the toll roads. The third stage is the implementation of the annual toll road policy, forming a diversified investment and financing pattern of state investment, local financing, social financing, and foreign capital utilization. BOT mode has been introduced into the expressway in all parts of China, but the failure of BOT operation is worrisome. In addition, after the initiation and development of highway, highway construction gradually to the small population, underdeveloped and complex geological conditions in the western region, the construction cost is more expensive, the average cost per kilometer into million yuan or even exceeded million yuan. The high cost of construction and the heavy burden of repayment make it more difficult for the market to finance. Most of the expressways in China are government subsidized business toll roads. The traditional expressway financing mode is mainly composed of government financial subsidies and bank loans. Although some of the pilot projects have introduced some investment in foreign-funded enterprises at present, the investment subject still has limitations. The expansion of investment entities, the diversification of government and business cooperation and the diversification of social capital investment are conducive to the smooth completion of China's investment and financing system reform [4].

\subsection{Insufficient Preferential Policies}

Due to the small amount of traffic on the toll road, the rate of return on investment is low, and the lack of supporting preferential policies attract investment. Especially after entering the mountain area, the population is relatively less, the economy is less developed, and the traffic volume of the expressway is far from the average level of the city. In general, market capital in the construction of the investment Highway, the rate of return for investment is more than $10 \%$. In fact, the investment return rate of some highway construction projects is low, so it is difficult to attract social capital investment, unless the corresponding supporting policies are provided to ensure that investors get a reasonable return on investment. In the implementation of infrastructure, heavy debt has restricted the construction and development of expressways and has an impact on the further economic development and construction of the country. In terms of investment and financing channel is relatively single, central government and local government in this regard as a management and investment role, because of the monopoly in highway construction makes the construction fund shortage problem is more prominent, the local government pressure on debt is large, has a great 
influence on the investment and financing mode of highway construction single. The current debt level of our country is not more than eighty percent, which is strictly regulated. Therefore, the enterprise will take the way of project financing, so that the cost will be higher than the traditional financing cost, such as the initial cost of the project. The highway with public property, in order to facilitate the successful implementation of PPP project of highway, provide more high-quality public products and services to the public, the government from the overall situation, have the right to tax relief PPP item company; secondly, project investment, project until after the completion of many years there will be great pressure owing on the loan and cash flow, for the smooth implementation of PPP security project, prevent item company capital chain rupture, the government of all or part of tax relief for the item company, but also the support of the private sector, reduce the investment in large-scale public welfare facilities to fund risk. Therefore, tax incentives are often used in the PPP project on the highway.

\section{Suggestions of Highway Construction Financing Under the PPP Model}

\subsection{Perfect Legal System}

As a financing mode for initial development and application in road traffic construction, the PPP mode needs to be perfected through laws and regulations, and rigid regulations are made from the system to safeguard the interests of both sides and reduce the risk of cooperation between the two sides. An operating highway refers to a toll road built by a government or a civil economy organization. The government loan repayment highway refers to the toll road constructed by the government related departments through the financing of the bank or the enterprise. The application of a type of toll road is only suitable for a short term preliminary exploration, and the PPP model needs a long-term development. In the two types of toll road construction in full expansion, the original property of the new division and adjustment. The responsibility and obligations of the two parties involved in the construction of highway traffic are guided by the system, and the responsibility for the risks and interests is clearly defined. To prevent the disputes and contradictions involved, and to put forward the treatment methods and opinions. Only by perfecting and defining relevant systems can we improve the participation of private capital organizations, so that PPP mode can be successfully developed and applied in road traffic construction. Perfect the laws and regulations is an important factor in the effective construction of the PPP project, the parties clearly need to take in the PPP project in the legal responsibility, function, obligation and need to bear the risk problem, the likelihood of risk, how to allocate, must have a clear legal basis, and according to the laws and regulations, to ensure the effective cooperation between the two sides. At the same time, in the PPP project operation but also to ensure the standardized operation, also need to establish and perfect the corresponding laws and regulations, and in accordance with the operation, it also largely avoided the possible cooperation in the dispute, convenient management and project operation, improve the efficiency and scientific cooperation.

\subsection{Reduce Finance Risk}

According to the practical operability of the project, combined with the current and long-term development direction, we can predict the possible risks and determine the possibility of its occurrence. Due to the particularity of long road construction and large volume of projects, to ensure the interests of both sides in the construction process, we must take corresponding measures for the risks brought by PPP financing mode to ensure the interests of both sides. First, from the perspective of government, PPP financing can reduce the government's financial burden and attract other funds to participate in public construction projects, but on the choice of partners, the government needs to consider its experience and funds in similar projects. Secondly, from the perspective of managers, we need to analyze the background of the project, the actual situation, the investment return and the prospects, and then identify the source of funds, raise funds and ensure adequate project funds. Finally, when signing agreements between government and partners, we should clarify how to 
allocate benefits, how to bear risks, and how to withdraw from investors. We should clarify their responsibilities and responsibilities and share risks together to jointly prevent possible problems. The government and relevant departments should be based on the risk assessment, according to the degree of influence of various kinds of risks, and consider the current situation of the highway PPP project and long-term objectives, through the development of appropriate risk control and risk management measures, formulate various risk management plan, according to the comprehensive consideration of project risk assessment results and the cost of risk management and other factors, to find out the optimal risk countermeasures. The government should not only be a good supervisor, but also exert the strength of the masses on the one hand. On the other hand, it is necessary to establish a social monitoring organization which is not related to the relevant construction projects, and they shall jointly supervise and play the power of the masses. Therefore, under the condition of insufficient construction funds, the financing risk will be transferred to the relevant construction sector, which reduces the safety of financing risk and improves the financing risk coefficient.

\subsection{Strengthen Construction Management}

In highway construction, both the government and the construction units should take the quality as the center to strengthen the management, the government should set up the scheme design, construction standards, groups of inspectors note, the progress of construction in accordance with the agreement by professional verification, and the problems of accountability, given the duties within the scope of the support for the problems in the construction, to ensure the smooth operation of project construction. After the completion of the project, the construction unit shall transfer the project according to the contract and mark other facilities and facilities involved in the project construction and confirm the details of the transfer. In addition, due to the professionalism and complexity of PPP mode application, to work more efficiently, we need to increase the introduction of professionals, and improve the professional level of managers to ensure the smooth progress of road traffic construction. The PPP mode of expressway should establish a reasonable risk sharing mechanism, which embodies the principle that the party can take the most to control the risk. Because some item company have not introduced trust investment, asset securitization and other financial tools in the construction of expressway projects, showing a relatively simple financing method. This problem is very prone to cause risk accumulation phenomenon, resulting in financing crisis. The PPP project includes debt risk, overspending, business risk, market risk, and technical risk to the private sector, all undertaken by the private sector. The government's public sector has more advantages to deal with political and financial risks. Give full play to the advantages of both public and private parties, share the risk, then the whole project risk will be reduced to the minimum, so that the successful implementation of the PPP project. The contract clearly the private sector responsibility, clear rewards and punishment regulations, though, promote public projects to reduce the cost, achieve the goal on schedule, with public sector standards of products and services to the public.

\section{Conclusions}

The expressway is the basic traffic engineering which has been developed vigorously in our country. In the construction of the project, the application of PPP model risk management can effectively improve the management level and has a good application value. Governments and enterprises should adopt effective measures to manage their shared risks and help each other to manage risks to ensure the normal progress of the project.

\section{References}

[1] Yan Zhebin. Research on Application of PPP Mode in Non-toll Highway [J]. Western China Communications Science \& Technology, 2017(3): 121-124.

[2] Liu Guangping, Chen Liwen, Pan Hui, et al. Decision-Making on the Partners Investment Ratio and Concession Term of PPP Highway Project [J]. Industrial Engineering Journal, 2014, 17(4): 
42-46.

[3] Mao Kejun. Experience Study of the Toll Highway PPP Practice [J]. China Transportation Review, 2015, 37(9): 70-74.

[4] Song Yang. Project Financing Risks and Countermeasures of Highway Construction Under the PPP artnership Mode [J]. Construction \& Design for Engineering, 2017(6): 190-193. 